Article

\title{
Quali-Quantitative Profile of Native Carotenoids in Kumquat from Brazil by HPLC-DAD-APCI/MS
}

\author{
Helena Maria Pinheiro-Sant'Ana ${ }^{1}$, Pamella Cristine Anunciação ${ }^{1}\left(0\right.$, , Clarice Silva e Souza ${ }^{1}$, \\ Galdino Xavier de Paula Filho ${ }^{2}$, Andrea Salvo ${ }^{3, *}$, Giacomo Dugo ${ }^{3}$ and Daniele Giuffrida ${ }^{3}$ (D) \\ 1 Departamento de Nutrição e Saúde, Universidade Federal de Viçosa, Avenida P.H. Rolfs, s/n, \\ Viçosa 36571-000, Brazil; helena.santana@ufv.br (H.M.P.-S.); nutripamella@gmail.com (P.C.A.); \\ cla_souzabio@yahoo.com.br (C.S.e.S.) \\ 2 Departamento de Educação, Universidade Federal do Amapá, Rodovia Juscelino Kubitschek, Km 02, \\ Jardim Marco Zero, Macapá 68903-419, Brazil; galdinoxpf@gmail.com \\ 3 Department, of Biomedical and Dental Sciences and Morphofunctional Imaging, University of \\ Messina (Italy), V.le Annunziata, 98168 Messina, Italy; dugog@unime.it (G.D.); dgiuffrida@unime.it (D.G.) \\ * Correspondence: asalvo@unime.it; Tel.: +39-090-676-6880
}

Received: 3 April 2019; Accepted: 14 May 2019; Published: 16 May 2019

\begin{abstract}
In this study the native carotenoids composition in kumquat (Fortunella margarita) (peel + pulp) from Brazil was determined for the first time by a HPLC-DAD-APCI/MS (high performance liquid chromatography-diode array detector-atmospheric pressure chemical ionization/mass spectrometry), methodology. Eleven carotenoids were successfully identified and quantified in kumquat: four carotenoids in the free form and seven carotenoids in the esterified form. $\beta$-citraurin-laurate was the carotenoid found in the highest content $(607.33 \mu \mathrm{g} / 100 \mathrm{~g}$ fresh matter), followed by $\beta$-cryptoxanthin-laurate $(552.59 \mu \mathrm{g} / 100 \mathrm{~g})$. The different esterified forms of $\beta$-citraurin and $\beta$-cryptoxanthin represented $84.34 \%$ of the carotenoids found, which demonstrates the importance of esterification in natural fruits. $\beta$-carotene and free xanthophylls ( $\beta$-cryptoxanthin, lutein and zeaxanthin) represented $5.50 \%$ and $14.96 \%$, respectively, of total carotenoids in kumquat. The total carotenoid content of kumquat from Brazil was very high $(2185.16 \mu \mathrm{g} / 100 \mathrm{~g})$, suggesting that this fruit could contribute significantly to the intake of important bioactive compounds by the population.
\end{abstract}

Keywords: Fortunella margarita; citrus; carotenes; xanthophylls; $\beta$-citraurin-laurate; $\beta$-cryptoxanthinlaurate

\section{Introduction}

The citrus family is one of the first crops in the world, it is estimated that half of the marketed production comes from the Americas and 12\% comes from the Mediterranean basin. Citrus cultivation is thought to date back at least 4000 years and is mainly from the Asiatic south-east territories. The estimated global citrus traffic for 2017-2018 was around 6 million tons. The most representative cultures were Citrus sinensis (61\%), Citrus reticulata (22\%), Citrus limon (11\%) and Citrus paradisi (6\%). In the Americas, the primacy of citrus production lies with Brazil followed by the United States. Sweet oranges are grown in Brazil, mainly in the state of São Paulo, over an area of about 584000 hectares, but also in the Amazonas area of northern Brazil, over about 2.7 hectares. [1].

The Citrus japonica, known by the common names of kincan (from Japanese kinkan) or cunquate (from Chinese kumquat), is a small citrus fruit of the Rutaceae family [2]. It has four major cultivated types, including Fortunella japonica, Fortunella margarita, Fortunella crassifolia, and Fortunella hindsii [3].

In eastern countries, this fruit is a part of the regular food habits of the population [4], but in Brazil it is considered exotic, in addition to being little known and commercialized. Among the Brazilian states, São Paulo has the largest production and commercialization of this fruit [5]. 
Kumquats are native to Central China. They are oval or round fruits with peel and orange smooth. Its flavor varies from acid to sweet. The fruit is rich in vitamins, carotene, pectin, calcium, phosphorus, iron and flavonoids [6]. Kumquats are consumed preferably in natura, whole and in shell. It is also used to make jellies, mousse, jams, marmalades, liqueurs and cachaça [7], preparation of syrups, sauces and also, accompaniment in fruit salads and for landscaping purposes and ornamentation [8,9].

Citrus japonica has been used as a traditional folk medicine in Asian countries to reduce alcohol intoxication and as antidepressants, so they are used either as medicines or as edible fruit [10]. Many studies on antioxidant, antimicrobial and antitumor effects have been carried out on kumquats, however identification of the bioactive compounds in the fruit has received little attention [11].

The most elucidated chemical components in kumquat described in the literature are phenolics compounds and flavonoids. Different phenolic compounds and flavonoids are described in Fortunella sp. by HPLC-MS [12,13]. These studies have shown a higher concentration of phenolics in fruit peels, with luteolin and kaempferol being the main flavonoids found in Fortunella sp. [8,14-17].

Studies on carotenoids in kumquat are extremely limited [9,18-20]. Agócs et al. [18] studied the qualitative and quantitative composition of carotenoids of kumquat and other citrus species. However, the sample preparation of the carotenoids involved a saponification step, a procedure that does not allow us to evaluate the native composition of the carotenoids.

Studies on the composition of carotenoids in foods are very important because they participate in various biological processes in plants, such as photosynthesis, photomorphogenesis, photoprotection, and development [21]. In animals, provitamin A carotenoids play an essential role in the synthesis of retinol (vitamin A) [22], whereas the xanthophylls lutein and zeaxanthin have been associated in humans with the prevention of age-ralated eye degenerations $[23,24]$.

Carotenoids are molecules made up of a long chain of usually forty carbon atoms; they can by divided into two classes: (a) non oxygenated one named carotenes [25] and (b) oxygenated one named xanthophylls [26]. Moreover, the xanthophylls are usually esterified with fatty acids in nature.

The studies on the content of carotenoids in kumquats concern plants grown in Asia but data are not available for fruits harvested in Brazil $[18,19]$. Therefore, this work aimed to determine the complete qualitative and quantitative profile of the kumquat carotenoid native composition for fruits collected in the rural area of Viçosa, Minas Gerais, Brazil, through liquid chromatography coupled to the mass detector (HPLC-DAD-APCI-MS).

\section{Materials and Methods}

\subsection{Chemicals}

The standards of $\beta$-carotene, $\beta$-cryptoxanthin, lutein, zeaxanthin and physalein, Standard purity was above $98 \%$ were purchased from Extrasynthese (Genay, France), and the solvents $\mathrm{MeOH}$ (Methanol), MTBE (Methyl-t-butyl ether) and $\mathrm{H}_{2} \mathrm{O}$ (Water) from Sigma-Aldrich (Milan, Italy).

\subsection{Collection and Preparation of the Samples}

The fruits of kumquat (Fortunella margarita) (Figure 1) were collected in the morning, in May 2017, in the rural area of Viçosa (latitude $20^{\circ} 44^{\prime} 05^{\prime \prime} \mathrm{S}$ and longitude $42^{\circ} 51^{\prime} 27^{\prime \prime} \mathrm{W}$ ), Minas Gerais, Brazil. Samples were collected in four repetitions of approximately $1 \mathrm{~kg}$ each. The fruit maturation was determined according to Donadio et al. [27] and defined by the red-orange peel color and the characteristic smell. In addition, ripe fruits were considered as those obtained after their natural fall of the trees or fall after being lightly touched by the hands.

The species was identified with the help of taxonomists from the Universidade Federal de Viçosa Herbarium through the Angiosperm Phylogeny Group IV [28], where it has already been cataloged and registered in the Virtual Herbarium network with the following records: EAC 48987, HUCO 5197, HPL 8977 and SP 42766. 
The samples were transported from the harvest site to the laboratory protected in styrofoam boxes with blocks of ice, within two hours after collection. In the laboratory, the samples were selected for appearance, excluding those with any epidermis injury or mechanical damage due to transport. The fruits were removed from the seeds (peel + pulp) were homogenized in a food processor (RI 7625, Philips, São Paulo Brazil), lyophilized (Liotop-LP510, Liobras, São Carlos, Brazil) and stored in plastic containers with screw caps, covered with aluminum foil stored at $-18 \pm 1{ }^{\circ} \mathrm{C}$ until further analyses.

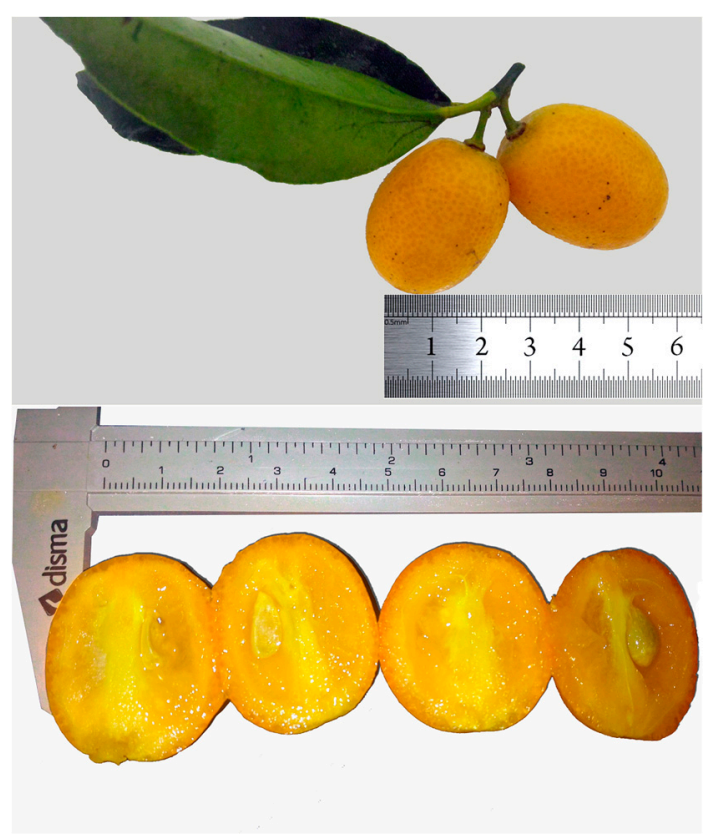

Figure 1. Kumquat (whole fruit and cross-section) from Viçosa, Minas Gerais, Brazil.

\subsection{Moisture Analysis}

Moisture was determined in triplicate in the oven (SP 200, SP Labor ${ }^{\circledR}$, São Paulo, Brazil), at $65 \pm 1{ }^{\circ} \mathrm{C}$, for approximately $72 \mathrm{~h} \mathrm{[29].}$

\subsection{Extraction of Carotenoids}

The carotenoid pigments were extracted from the lyophilized material (peel + pulp), according to the recommended procedures by Rodrigues-Amaya et al. [30]. Three grams of the edible portion of the samples (peel + pulp) were crushed by the use of a mortar and pestle, and a few drops of distilled water were added and extracted to color exhaustion with $20 \mathrm{~mL}$ of acetone (7 times) in an ultrasonic bath (Labsonic LBS 1-H22.5, Treviglio, Bergamo, Italy) for 10 min each time. Then, the extracts were individually centrifuged (Awel MF20-R, Multifunction Refrigerated Centrifuge, Blain, France) at $4000 \mathrm{rpm}, 5^{\circ} \mathrm{C}$, for $10 \mathrm{~min}$ in order to withdraw clear solution on the top. The acetonic extracts were pooled together was concentrated to about $25 \mathrm{~mL}$, in a rotary evaporator (Buchi-heating bath B-491, Buchi, Milan, Italy) at temperature below $35^{\circ} \mathrm{C}$. The dry product was diluted with equal volumes $(25 \mathrm{~mL})$ of a mixture of ethyl ether and hexane (1:1) and distilled water $(50 \mathrm{~mL})$ and worked up with a separating funnel. The lipofilic phase, cleared by the hydrophilic impurities, was evaporated to dryness using a rotary evaporator (Buchi-heating bath B-491 at $35^{\circ} \mathrm{C}$, and the residue was dissolved in $2 \mathrm{~mL}$ of $\mathrm{MeOH} / \mathrm{MTBE}$ (1:1) and filtered in filter units (PTFE, $0.45 \mu \mathrm{m}, 13 \mathrm{~mm}$, Sigma Aldrich, Milan, Italy) prior to HPLC analysis. Samples were stored at $-20^{\circ} \mathrm{C}$ until they were analyzed.

\subsection{Analysis of Carotenoids by HPLC-DAD-APCI-MS}

The analysis was performed on an HPLC system (Shimadzu, Kyoto, Japan) equipped with a CBM-20A controller, two LC-20AD pumps, a DGU-20A3R deaerator, a SIL-20AC autosampler, a CTO 
20AC column oven and an SPD-M20A photo diode array detector. The data were processed with the Labsolution software. For MS analysis a mass spectrometer detector (LCMS-8040) was used, equipped with an APCI (atmospheric pressure chemical ionization) interface, both in positive and negative ionization mode.

The column used was YMC C30 $(250 \mathrm{~mm} \times 4.6 \mathrm{~mm} \times 5 \mu \mathrm{m})$; the mobile phases: $\mathrm{MeOH} / \mathrm{MTBE} / \mathrm{H} 2 \mathrm{O}$ (81:15:4, solvent A), $\mathrm{MeOH} / \mathrm{MTBE} / \mathrm{H} 2 \mathrm{O}$ (6:90:4, solvent B); the linear gradient used was: $0-100 \%$ B from 0 to $140 \mathrm{~min}$. The column temperature was maintained at $30^{\circ} \mathrm{C}$. The flow was $0.8 \mathrm{~mL} / \mathrm{min}$ and the injection volume was $20 \mu \mathrm{L}$.

The UV-Vis spectra were acquired in the range $220-700 \mathrm{~nm}$, while the chromatograms were extracted at $450 \mathrm{~nm}$ (sampling frequency: $4.16 \mathrm{~Hz}$, time constant: $0.64 \mathrm{~s}$ ). The MS was set up as follows: Scan, both APCI positive (+) and negative (-); atomized gas flow (N2): $2.0 \mathrm{~L} / \mathrm{min}$; drying gas flow: $5 \mathrm{~L} / \mathrm{min}$; Time of the event: $0.06 \mathrm{~s}$; range $\mathrm{m} / \mathrm{z}$ : 300-1200; interface temperature: $350{ }^{\circ} \mathrm{C}$; Desolvation line (DL) temperature: $300^{\circ} \mathrm{C}$; thermal block: $300^{\circ} \mathrm{C}$. The samples were analyzed in triplicate.

\subsection{Identification and Quantification of Carotenoids}

Carotenoids were identified by their UV-Vis spectra, MS spectra, elution order, comparison with the available standard and literature data.

The kumquat carotenoids quantification was performed from the analytical curves. External standards quantitative determination of each compound was performed using all reference materials listed in Section 2.1, in the concentration range from 5 to $50 \mu \mathrm{g} / \mathrm{mL}$ at six concentration levels. The results were obtained from the average of three determinations and the CV\% was below $8 \%$ in all the LC measurements. The $R$ coefficient for the calibration curves was always above 0.9962 , with LOD and LOQ values of 0.07 and $0.22 \mathrm{ppm}$ for $\beta$-carotene, 0.1 and $0.33 \mathrm{ppm}$ for $\beta$-cryptoxanthin, 0.06 and $0.18 \mathrm{ppm}$ for lutein, 0.08 and $0.3 \mathrm{ppm}$ for zeaxanthin, and 0.12 and $0.24 \mathrm{ppm}$ for physalein, respectively.

\section{Results and Discussion}

\subsection{Carotenoids Qualitative Profile of Brazilian Kumquat}

Figure 2 shows the chromatographic profile of the carotenoid composition in not saponified kumquat fruits extracts. The identified compounds are shown in Table 1, together with the UV-Vis and MS spectra information. In Figure 3 are reported the UV-Vis (PDA) and mass spectrum of $\beta$-citraurin-laurate and $\beta$-citraurin-myristate, detected in the kumquat carotenoid extracts. It can be appreciated that the esterification does not affect the PDA spectra of $\beta$-citraurin.

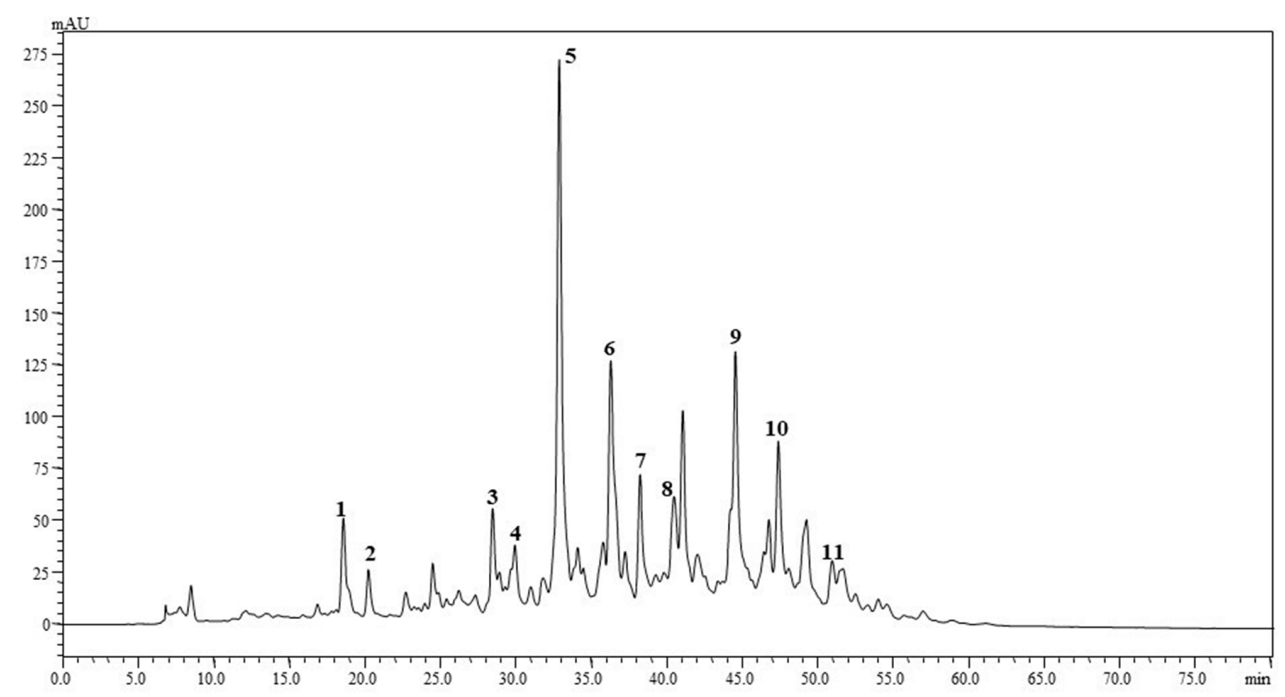

Figure 2. Chromatographic profile of native carotenoids of kumquat from Brazil: peel + pulp. Identification of the compounds are in Table 1. 
Table 1. Compounds identification for Figure 2 (kumquat from Brazil: peel + pulp).

\begin{tabular}{ccccc}
\hline Compound & Identification & Rt $(\mathbf{m i n})$ & PDA $(\boldsymbol{\lambda} \mathbf{n m})$ & MS (APCI-) $\mathbf{m} / \mathbf{z}$ \\
\hline 1 & Lutein & 18.5 & 445,473 & 568 \\
2 & Zeaxanthin & 20.2 & 449,476 & 568 \\
3 & $\beta$-cryptoxanthin & 28.4 & $428,451,478$ & 552 \\
4 & $\beta$-citraurin-caproate & 29.9 & 454 & 586 \\
5 & $\beta$-citraurin-laurate & 32.8 & 455 & 614 \\
6 & $\beta$-citraurin-myristate & 36.2 & 453 & 642 \\
7 & $\beta$-carotene & 38.1 & $426,451,476$ & 536 \\
8 & $\beta$-citraurin-palmitate & 40.4 & 455 & 642 \\
9 & $\beta$-cryptoxanthin-laurate & 44.5 & $428,450,478$ & 734 \\
10 & $\beta$-cryptoxanthin-myristate & 47.3 & $428,450,477$ & 762 \\
11 & $\beta$-cryptoxanthin-palmitate & 50.9 & $428,451,478$ & 790 \\
\hline
\end{tabular}

Rt: retention time; PDA: photodiode array; $\lambda \mathrm{nm}$ : wavelength of maximum absorption; MS: mass spectrometry; APCI: atmospheric pressure chemical ionization.
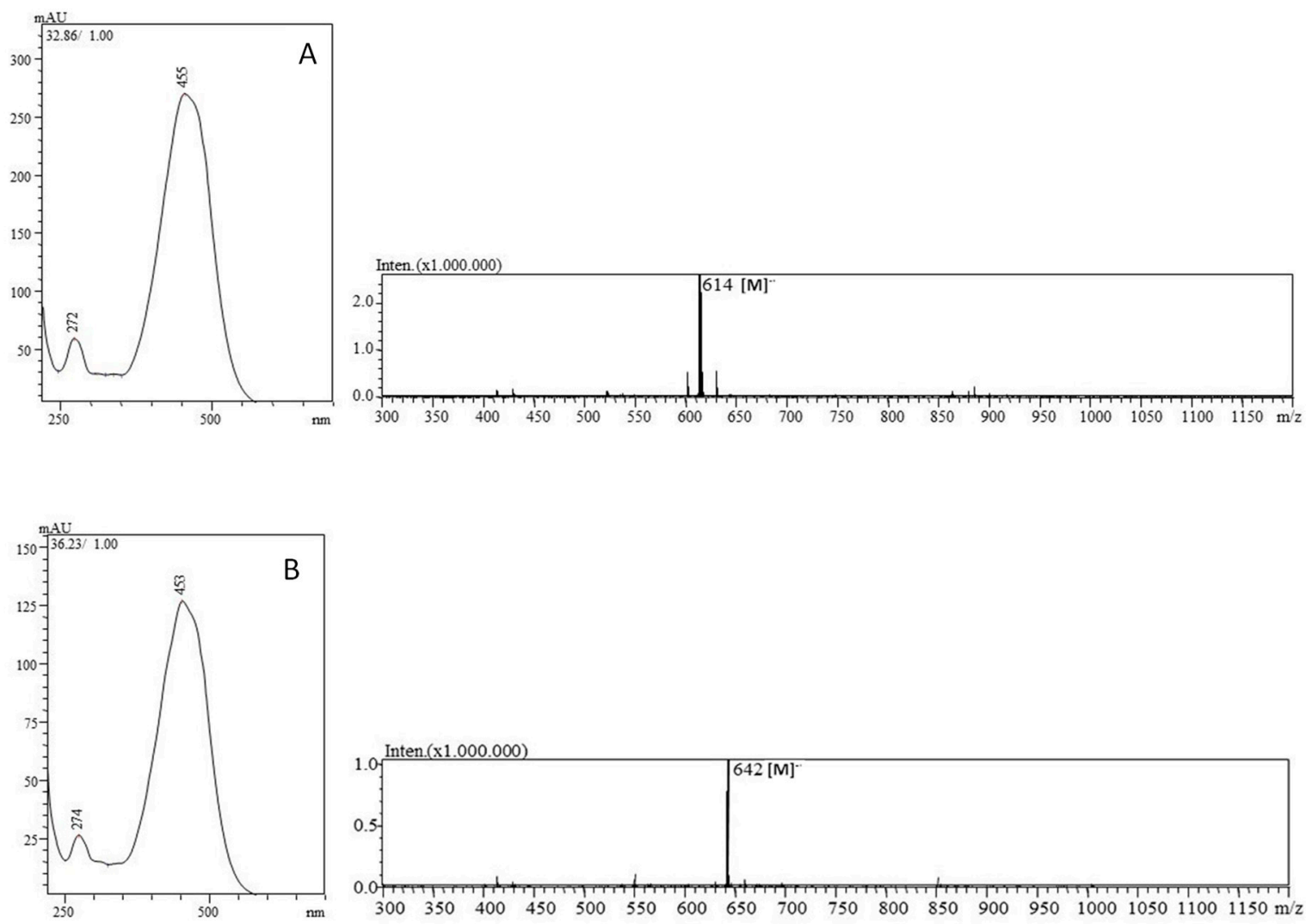

Figure 3. UV-Vis (PDA) and mass spectrum (APCI negative) of $\beta$-citraurin-laurate (A) and $\beta$-citraurinmyristate (B) of kumquat from Brazil.

Moreover, both the molecular ions $[\mathrm{M}]^{-\bullet}$ at respectively $\mathrm{m} / \mathrm{z} 614$ and $\mathrm{m} / \mathrm{z} 642$ relative to the $\beta$-citraurin-laurate and $\beta$-citraurin-myristate esters, obtained in the negative APCI mode, are also clearly shown in the same figure. Eleven different carotenoids were identified in kumquat from Brazil; four different $\beta$-citraurin esters and three $\beta$-cryptoxanthin esters were identified.

The predominant carotenoids were $\beta$-citraurin-laurate and $\beta$-cryptoxanthin-laurate, both esterified with lauric acid. The chemical structures of these carotenoids are shown in Figure 4. Interestingly, no free $\beta$-citraurin was detected in the present study. 

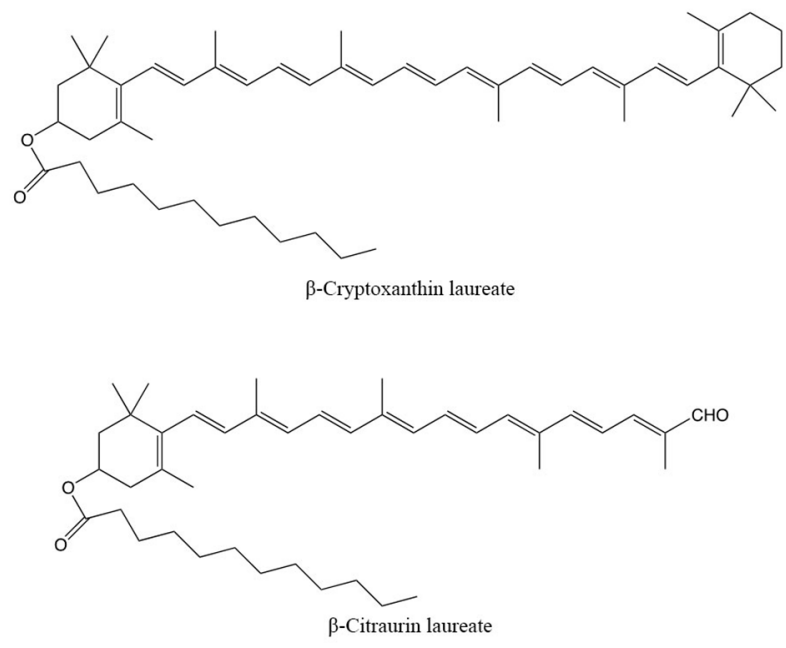

Figure 4. Chemical structures of $\beta$-cryptoxanthin-laurate and $\beta$-citraurin-laurate, main carotenoids detected in kumquat.

Shirra et al. [9] detected only 4 carotenoids in kumquat from Italy without saponification ( $\beta$-carotene, $\beta$-cryptoxanthin, lutein and zeaxanthin), which were also detected in the present study. In contrast to our study, Agos et al. [18] reported only $\beta$-citraurin and $\beta$-cryptoxanthin in the free form in kumquat from Hungary. However, these researchers used saponification after the extraction process and did not quantify the carotenoid esters. Saponification may result in destruction or structural transformation of carotenoids [31]. Huyskens et al. [19] studied the qualitative composition of kumquat carotenoids from Israel by thin-layer chromatography and reported several carotenoids, including $\beta$-citraurin, $\beta$-cryptoxanthin, lutein, $\beta$-carotene and zeaxanthin which were, also determined in the present study. In addition, Huyskens et al. [19] reported that violaxanthin was the predominant component in kumquat from Israel, whereas in our study $\beta$-citraurin-laurate was the major component.

Esterification with saturated fatty acids improves the stability of xanthophylls such as $\beta$-citraurin and $\beta$-cryptoxanthin against heat and UV light, but does not affect their antioxidant activity [32]. During the storage and processing of the fruits the xanthophyll esters were more stable than the free xanthophyll [33]. The pigment $\beta$-citraurin is responsible for the citrus reddish color, it derives from of $\beta$-cryptoxanthin or zeaxanthin and accumulates in some citrus varieties [34,35]. In these fruits, the accumulation of $\beta$-citraurin is not a common event, it is observed only in the flavedos of some varieties during fruit ripening [34]. Frutita, a tropical fruit from Panama, showed a very high content of $\beta$-citraurin [36].

Recent studies have shown that $\beta$-cryptoxanthin and $\beta$-citraurin esterified with lauric acid, myristic acid and palmitic acid are found in the Mandarin Satsuma, [35].

The dietary intake of $\beta$-cryptoxanthin has been shown to prevent and reduce some pathologies such as: cancer, diabetes and rheumatism due to its antioxidant activity [37-39]. Breithaupt et al. [40] have verified that in chili, papaya, peach and persimmon, $\beta$-cryptoxanthin is mainly esterified with saturated fatty acids. Furthermore, the bioavailability of $\beta$-cryptoxanthin esters is comparable to the non-esterified form, since fatty acids can be effectively hydrolyzed by $\beta$-cryptoxanthin esters before intestinal absorption in the human body [40]. In several citrus varieties, the esterified form $\beta$-citraurin is found [35]. As already observed in another study [41], we have found $\beta$-cryptoxanthin and $\beta$-citraurin in both free and esterified forms.

\subsection{Carotenoids Quantitative Profile of Brazilian Kumquat}

In the present study, $\beta$-citraurin-laurate was the carotenoid found in the highest content in kumquat from Brazil ( $607.33 \mu \mathrm{g} / 100 \mathrm{~g}$ fresh matter, representing $27.80 \%$ of total carotenoids), followed by $\beta$-cryptoxanthin-laurate ( $552.59 \mu \mathrm{g} / 100 \mathrm{~g}$ fresh matter, representing $25.31 \%$ of total carotenoids). Thus, $\beta$-citraurin-laurate and $\beta$-cryptoxanthin-laurate represented $53.11 \%$ of the total carotenoids 
found. The different forms of $\beta$-citraurin ( 4 components esterified with fatty acids) and $\beta$-cryptoxanthin ( 1 component in free form and 3 in esterified form) represented $84.34 \%$ of the carotenoids found in kumquat from Brazil. Forms of $\beta$-citraurin and $\beta$-cryptoxanthin esterified with fatty acids accounted for $79.54 \%$ of the total carotenoids in kumquat. These results show the importance of the study of the intact carotenoids composition in different matrices (Table 2).

Table 2. Carotenoid content in kumquat from Brazil (peel + pulp).

\begin{tabular}{|c|c|c|c|c|}
\hline Compound & Carotenoid & $\begin{array}{l}\text { Content in Lyophilized } \\
\text { Kumquat }(\mu \mathrm{g} / 100 \mathrm{~g}) *\end{array}$ & $\begin{array}{c}\text { Content in Fresh } \\
\text { Kumquat }(\mu \mathrm{g} / 100 \mathrm{~g}) *\end{array}$ & $\begin{array}{c}\text { Carotenoid } \\
\text { Composition (\%) }\end{array}$ \\
\hline 1 & Lutein & $873.05 \pm 93.51$ & $144.35 \pm 15.45$ & 6.61 \\
\hline 2 & Zeaxanthin & $469.55 \pm 25.52$ & $77.63 \pm 4.21$ & 3.55 \\
\hline 3 & $\beta$-Cryptoxanthin & $634.93 \pm 55.91$ & $104.98 \pm 9.25$ & 4.80 \\
\hline 4 & $\beta$-Citraurin-caproate & $721.81 \pm 20.04$ & $119.34 \pm 3.32$ & 5.46 \\
\hline 5 & $\beta$-Citraurin-laurate & $3673.28 \pm 81.78$ & $607.33 \pm 13.63$ & 27.80 \\
\hline 8 & $\beta$-Citraurin-palmitate & $801.27 \pm 66.35$ & $132.48 \pm 10.98$ & 6.06 \\
\hline 9 & $\beta$-Cryptoxanthin-laurate & $3342.25 \pm 126.10$ & $552.59 \pm 20.75$ & 25.31 \\
\hline 10 & $\beta$-Cryptoxanthin-myristate & $927.77 \pm 82.92$ & $153.39 \pm 13.71$ & 7.02 \\
\hline 11 & $\beta$-Cryptoxanthin-palmitate & $623.73 \pm 46.34$ & $103.13 \pm 7.67$ & 4.72 \\
\hline \multicolumn{2}{|l|}{ Total carotenes } & 726.96 & 120.19 & 5.50 \\
\hline
\end{tabular}

${ }^{*}$ Mean of 3 repetitions \pm standard deviation (SD). The carotenoid content in the fresh kumquat was calculated based on the average moisture content $(n=3)$ of the lyophilized fruit $(14.08 \%)$ and the fresh fruit $(81.16 \%)$.

$\beta$-carotene was found in smaller amounts $(120.19 \mu \mathrm{g} / 100 \mathrm{~g}$ fresh matter), representing $5.50 \%$ of total carotenoids in kumquat, as well as free xanthophylls ( $\beta$-cryptoxanthin, lutein and zeaxanthin), which represented $14.96 \%$ of total carotenoids $(326.96 \mu \mathrm{g} / 100 \mathrm{~g})$ (Table 2$)$. $\beta$-carotene and $\beta$-cryptoxanthin possess provitamin A activity, playing a key role in human health [42]. Differently from our results, Wang et al. [20] reported that $\beta$-cryptoxanthin was the major carotenoid present in kumquat cultivated in Taiwan, while Schirra et al. [9] found lutein to be the major carotenoid present in kumquat from Italy.

Schirra et al. [9] found a lower concentration, in fresh matter, of $\beta$-carotene $(33 \mu \mathrm{g} / 100 \mathrm{~g})$, $\beta$-cryptoxanthin $(26 \mu \mathrm{g} / 100 \mathrm{~g})$, lutein $(44 \mu \mathrm{g} / 100 \mathrm{~g})$ and zeaxanthin $(24 \mu \mathrm{g} / 100 \mathrm{~g})$ in kumquat from Italy when compared to the concentrations of these carotenoids in kumquat from Brazil, reported here for the first time. Wang et al. [41] found contents in dry matter that were much lower than reported here, for lutein $(9.9 \mu \mathrm{g} / 100 \mathrm{~g})$, zeaxanthin $(10.4 \mu \mathrm{g} / 100 \mathrm{~g}), \beta$-cryptoxanthin $(183 \mu \mathrm{g} / 100 \mathrm{~g})$ and $\beta$-carotene $(131 \mu \mathrm{g} / 100 \mathrm{~g})$ in kumquat cultivated in Taiwan. Carotenoid composition and contents in fruits can be influenced by genetic factors, geographical regions, fruit processing, storage methods Giuffrida et al. [25] and environmental conditions Lu et al. [26], which can explain the differences found in these studies. Besides the climatic factors, the irrigation, soil conditions, fertilizers and herbicides may also affect the carotenoids accumulation [26]. Regarding the carotenoids content in food, Britton [43] have proposed the following classification ranges: low: 0-0.1 mg/100 g; moderate: $0.1-0.5 \mathrm{mg} / 100 \mathrm{~g}$; high: $0.5-2 \mathrm{mg} / 100 \mathrm{~g}$; very high: $>2 \mathrm{mg} / 100 \mathrm{~g}$. Thus, the total carotenoid content of kumquat from Brazil was very high $(2185.16 \mu \mathrm{g} / 100 \mathrm{~g})$.

\section{Conclusions}

In this study the native carotenoids composition in kumquat (Fortunella margarita) from Brazil was determined for the first time. Eleven native carotenoids in kumquat from the rural area of Minas Gerais, Brazil were successfully identified and quantified by HPLC-DAD-APCI-MS. Four carotenoids in the free form ( $\beta$-carotene, $\beta$-cryptoxanthin, lutein and zeaxanthin) and 7 carotenoids in the esterified form were identified ( $\beta$-citraurin-caproate, $\beta$-citraurin-laurate, $\beta$-citraurin-myristate, $\beta$-citraurin-palmitate, $\beta$-cryptoxanthin-laurate, $\beta$-cryptoxanthin-myristate, $\beta$-cryptoxanthin-palmitate). $\beta$-citraurin-laurate and $\beta$-cryptoxanthin-laurate were the most abundant native carotenoids in kumquat from Brazil. The 
total carotenoid content of kumquat from Brazil was high $(2185.16 \mu \mathrm{g} / 100 \mathrm{~g})$, suggesting that this fruit can contribute significantly to the ingestion of important bioactive compounds.

Author Contributions: Conceptualization, H.M.P.-S., P.C.A.; Methodology, C.S.e.S., G.X.d.P.F.; Writing-review and editing, A.S.; Supervision, G.D., and D.G.

Funding: This research received no external funding.

Acknowledgments: The authors thanks the Fundação de Amparo à Pesquisa do Estado de Minas Gerais (FAPEMIG), the Conselho Nacional de Desenvolvimento Científico e Tecnológico (CNPq), the Coordenação de Aperfeiçoamento de Ensino Superior (CAPES) and the Università degli Studi de Messina for financial support for conduction of the study.

Conflicts of Interest: The authors declare no conflict of interest.

\section{References}

1. Instituto Brasileiro de Geografia e Estatística. Pesquisa de Orçamentos Familiares; Ministério da Saúde: Rio de Janeiro, Brasília, 2009.

2. The Plant List. Available online: http://www.theplantlist.org/tpl/record/kew-2724150 (accessed on 15 May 2019).

3. Ogawa, K.; Kawasaki, A.; Omura, M.; Yoshida, T.; Ikoma, Y.; Yano, M. 3' ,5'-Di-C- $\beta$-glucopyranosylphloretin, a flavonoid characteristic of the genus Fortunella. Phytochemistry 2001, 57, 737-742. [CrossRef]

4. Pompeu Junior, J. Rootstocks and scions in the citriculture of the São Paulo State; In Proceedings of International Congress of Citrus Nurserymen, Ribeirão Preto, Brasil, 2001; pp. 75-82.

5. Watanabe, H.S.; De Oliveira, S.L. Comercialização de frutas exóticas. Revista Brasileira de Fruticultura 2014, 36, 23-38. [CrossRef]

6. Barreca, D.; Bellocco, E.; Caristi, C.; Leuzzi, U.; Gattuso, G. Kumquat (Fortunella japonica Swingle) juice: Flavonoid distribution and antioxidant properties. Food. Res. Int. 2011, 44, 2190-2197. [CrossRef]

7. Koller, O.L. Citricultura Catarinense; Epagri: Florianópolis, Brazil, 2013.

8. Kawaii, S.; Tomono, Y.; Katase, E.; Ogawa, K.; Yano, M. Quantitation of flavonoid constituents in citrus fruits. J. Agric. Food Chem. 1999, 47, 3565-3571. [CrossRef]

9. Schirra, M.; Palma, A.; D'Aquino, S.; Angioni, A.; Minello, E.V.; Melis, M.; Cabras, P. Influence of postharvest hot water treatment on nutritional and functional properties of kumquat (Fortunella japonica Lour. Swingle Cv. Ovale) fruit. J. Agric. Food Chem. 2007, 56, 455-460. [CrossRef]

10. Liu, Y.; Liu, Y.; Liu, Y.; Liu, H.; Shang, Y. Evaluating effects of ellagic acid on the quality of kumquat fruits during storage. Sci. Hortic. 2018, 227, 244-254. [CrossRef]

11. Lou, S.N.; Ho, C.T. Phenolic compounds and biological activities of small-size citrus: Kumquat and calamondin. J. Food Drug Anal. 2017, 25, 162-175. [CrossRef] [PubMed]

12. Lou, S.N.; Lai, Y.C.; Hsu, Y.S.; Ho, C.T. Phenolic content, antioxidant activity and effective compounds of kumquat extracted by different solvents. Food Chem. 2016, 197, 1-6. [CrossRef] [PubMed]

13. Lou, S.N.; Lai, Y.C.; Huang, J.D.; Ho, C.T.; Ferng, L.H.A.; Chang, Y.C. Drying effect on flavonoid composition and antioxidant activity of immature kumquat. Food Chem. 2015, 171, 356-363. [CrossRef] [PubMed]

14. Chen, M.H.; Yang, K.M.; Huang, T.C.; Wu, M.L. Traditional small-size citrus from Taiwan: Essential oils, bioactive compounds and antioxidant capacity. Medicines 2017, 4, 28. [CrossRef]

15. Salvo, A.; Bruno, M.; La Torre, G.L.; Vadalà, R.; Mottese, A.F.; Saija, E.; Mangano, V.; Casale, K.E.; Cicero, N.; Dugo, G. Interdonato lemon from Nizza di Sicilia (Italy): Chemical composition of hexane extract of lemon peel and histochemical investigation. Nat. Prod. Res. 2016, 30, 1517-1525. [CrossRef]

16. Salvo, A.; Costa, R.; Albergamo, A.; Arrigo, S.; Rotondo, A.; La Torre, G.L.; Mangano, V.; Dugo, G. An in-depth study of the volatile variability of chinotto (Citrus myrtifolia Raf.) induced by the extraction procedure. Eur. Food Res. Technol. 2019. [CrossRef]

17. Costa, R.; Salvo, A.; Rotondo, A.; Bartolomeo, G.; Pellizzeri, V.; Saija, E.; Arrigo, S.; Interdonato, M.; Trozzi, A.; Dugo, G. Combination of separation and spectroscopic analytical techniques: Application to compositional analysis of a minor citrus species. Nat. Prod. Res. 2018, 32, 2596-2602. [CrossRef] [PubMed]

18. Agócs, A.; Nagy, V.; Szabó, Z.; Márk, L.; Ohmacht, R.; Deli, J. Comparative study on the carotenoid composition of the peel and the pulp of different citrus species. Innov. Food. Sci. Emerg. Technol. 2007, 8, 390-394. [CrossRef] 
19. Huyskens, S.; Timberg, R.; Gross, J. Pigment and plastid ultrastructural changes in Kumquat (Fortunella margarita) «Nagami» during ripening. J. Plant. Physiol. 1985, 118, 61-72. [CrossRef]

20. Wang, Y.C.; Chuang, Y.C.; Ku, Y.H. Quantitation of bioactive compounds in citrus fruits cultivated in Taiwan. Food Chem. 2007, 102, 1163-1171. [CrossRef]

21. Nisar, N.; Li, L.; Lu, S.; Khin, N.C.; Pogson, B.J. Carotenoid metabolism in plants. Mol. Plant 2015, 8, 68-82. [CrossRef] [PubMed]

22. Krinsky, N.I.; Johnson, E.J. Carotenoid actions and their relation to health and disease. Mol. Aspects Med. 2005, 26, 459-516. [CrossRef] [PubMed]

23. Fiedor, J.; Burda, K. Potential role of carotenoids as antioxidants in human health and disease. Nutrients 2014, 6, 466-488. [CrossRef]

24. Johnson, E.J.; Krinsky, N.I. Carotenoids and coronary heart disease. In Carotenoids; Springer: Basel, Switzerland, 2009; pp. 287-300.

25. Giuffrida, D.; Dugo, P.; Salvo, A.; Saitta, M.; Dugo, G. Free carotenoid and carotenoid ester composition in native orange juices of different varieties. Fruits 2010, 65, 277-284. [CrossRef]

26. Lu, Q.; Huang, X.; Lv, S.; Pan, S. Carotenoid profiling of red navel orange "Cara Cara" harvested from five regions in China. Food Chem. 2017, 232, 788-798. [CrossRef]

27. Donadio, L.C. Dicionário das Frutas; UNESP: Jaboticabal, Brazil, 2007.

28. The Angiosperm Phylogeny Group. An update of the Angiosperm Phylogeny Group classification for the orders and families of flowering plants: APG IV. Bot. J. Linn. Soc. 2016, 181, 1-20.

29. Association of Official Analytical Chemists (AOAC). Official Methods of Analysis of the Association of Official Analytical Chemists, 18th ed.; Association of Official Analytical Chemists: Washington, DC, USA, 2010.

30. Rodriguez-Amaya, D. Food Carotenoids: Chemistry, Biology and Technology; John Wiley \& Sons: Hoboken, NZ, USA, 2015.

31. Amorim-Carrilho, K.; Cepeda, A.; Fente, C.; Regal, P. Review of methods for analysis of carotenoids. Trends. Analyt. Chem. 2014, 56, 49-73. [CrossRef]

32. Fu, H.; Xie, B.; Fan, G.; Ma, S.; Zhu, X.; Pan, S. Effect of esterification with fatty acid of $\beta$-cryptoxanthin on its thermal stability and antioxidant activity by chemiluminescence method. Food Chem. 2010, 122, 602-609. [CrossRef]

33. Bunea, A.; Socaciu, C.; Pintea, A. Xanthophyll esters in fruits and vegetables. Not. Bot. Horti Agrobot. Cluj Napoca 2014, 42, 310. [CrossRef]

34. Ma, G.; Zhang, L.; Iida, K.; Madono, Y.; Yungyuen, W.; Yahata, M.; Yamawaki, K.; Kato, M. Identification and quantitative analysis of $\beta$-cryptoxanthin and $\beta$-citraurin esters in Satsuma mandarin fruit during the ripening process. Food Chem. 2017, 234, 356-364. [CrossRef]

35. Ma, G.; Zhang, L.; Matsuta, A.; Matsutani, K.; Yamawaki, K.; Yahata, M.; Wahyudi, A.; Motohashi, R.; Kato, M. Enzymatic formation of $\beta$-citraurin from $\beta$-cryptoxanthin and zeaxanthin by carotenoid cleavage dioxygenase4 in the flavedo of citrus fruit. Plant Physiol. 2013, 163, 682-695. [CrossRef]

36. Murillo, E.; Giuffrida, D.; Menchaca, D.; Dugo, P.; Torre, G.; Meléndez-Martinez, A.J.; Mondello, L. Native carotenoids composition of some tropical fruits. Food Chem. 2013, 140, 825-836. [CrossRef]

37. Iskandar, A.R.; Liu, C.; Smith, D.E.; Hu, K.Q.; Choi, S.W.; Ausman, L.M.; Wang, X.D. $\beta$-Cryptoxanthin restores nicotine-reduced lung SIRT1 to normal levels and inhibits nicotine-promoted lung tumorigenesis and emphysema in A/J mice. Cancer Prev. Res. 2012, 6, 309-320. [CrossRef] [PubMed]

38. Takayanagi, K.; Morimoto, S.I.; Shirakura, Y.; Mukai, K.; Sugiyama, T.; Tokuji, Y.; Ohnishi, M. Mechanism of visceral fat reduction in Tsumura Suzuki obese, diabetes (TSOD) mice orally administered $\beta$-cryptoxanthin from Satsuma mandarin oranges (Citrus unshiu Marc). J. Agric. Food Chem. 2011, 59, 12342-12351. [CrossRef] [PubMed]

39. Yamaguchi, M. Role of carotenoid $\beta$-cryptoxanthin in bone homeostasis. J. Biomed. Sci. 2012, 19, 36. [CrossRef] [PubMed]

40. Breithaupt, D.E.; Weller, P.; Wolters, M.; Hahn, A. Plasma response to a single dose of dietary $\beta$-cryptoxanthin esters from papaya (Carica papaya L.) or non-esterified $\beta$-cryptoxanthin in adult human subjects: A comparative study. Br. J. Nutr. 2003, 90, 795-801. [CrossRef] [PubMed]

41. Wada, Y.; Matsubara, A.; Uchikata, T.; Iwasaki, Y.; Morimoto, S.; Kan, K.; Ookura, T.; Fukusaki, E.; Bamba, T. Investigation of $\beta$-cryptoxanthin fatty acid ester compositions in citrus fruits Cultivated in Japan. Food Nutr. Sci. 2013, 4, 98. 
42. Mercadante, A.Z.; Rodrigues, D.B.; Petry, F.C.; Mariutti, L.R.B. Carotenoid esters in foods-A review and practical directions on analysis and occurrence. Food Res. Int. 2017, 99, 830-850. [CrossRef] [PubMed]

43. Britton, G.; Khachik, F. Carotenoids in food. In Carotenoids; Britton, G., Pfander, H., Liaaen-Jensen, S., Eds.; Springer: Basel, Switzerland, 2009.

(C) 2019 by the authors. Licensee MDPI, Basel, Switzerland. This article is an open access article distributed under the terms and conditions of the Creative Commons Attribution (CC BY) license (http://creativecommons.org/licenses/by/4.0/). 